\title{
Mitochondrial DNA depletion syndrome
}

INSERM

\section{Source}

INSERM. (1999). Orphanet: an online rare disease and orphan drug data base.

Mitochondrial DNA depletion syndrome. ORPHA:35698

The mitochondrial DNA (mtDNA) depletion syndrome (MDS) is a clinically heterogeneous group of mitochondrial disorders characterized by a reduction of the mtDNA copy number in affected tissues without mutations or rearrangements in the mtDNA. MDS is phenotypically heterogeneous, and can affect a specific organ or a combination of organs, with the main presentations described being either hepatocerebral (i.e. hepatic dysfunction, psychomotor delay), myopathic (i.e. hypotonia, muscle weakness, bulbar weakness), encephalomyopathic (i.e. hypotonia, muscle weakness, psychomotor delay) or neurogastrointestinal (i.e gastrointestinal dysmotility, peripheral neuropathy). Additional phenotypes include fatal infantile lactic acidosis with methylmalonic aciduria, spastic ataxia (early-onset spastic ataxia-neuropathy syndrome), and Alpers syndrome. 